\title{
Associations between dietary patterns and demographics, lifestyle, anthropometry and blood pressure in Chinese community-dwelling older men and women
}

\author{
Ruth Chan $^{1 *}$, Dicken Chan $^{2}$ and Jean Woo ${ }^{1}$ \\ ${ }^{1}$ Department of Medicine and Therapeutics, The Chinese University of Hong Kong, Shatin, Hong Kong \\ ${ }^{2}$ Jockey Club Centre for Osteoporosis Care and Control, The Chinese University of Hong Kong, Shatin, Hong Kong
}

(Received 7 October 2011 - Final revision received 5 September 2012 - Accepted 28 September 2012)

Journal of Nutritional Science (2012), vol. 1, e20, page 1 of 10

doi:10.1017/jns.2012.19

Abstract

This cross-sectional study examined dietary patterns, and the associations of these patterns with demographics, lifestyle, anthropometry and blood pressure in 3707 Chinese people aged 65 years and above taking part in a population-based cohort study investigating the risk factors for osteoporosis. Baseline dietary data were collected using a validated FFQ. Dietary patterns were identified using factor analysis. Scores were calculated for each pattern. Demographics, lifestyle factors and self-reported hypertension history were collected through a questionnaire. BMI, waist circumference (WC), hip circumference (HC), waist-to-hip ratio, systolic blood pressure and diastolic blood pressure (DBP) were measured. Three dietary patterns were identified, namely 'vegetables-fruit', 'snacks-drinks-milk products' and 'meat-fish'. Participants who were more physically active, more educated, non-smokers and non-drinkers were more likely to have higher 'vegetables-fruit' dietary pattern scores. Current smoking habit and alcohol use were associated with higher 'snacks-drinks-milk products' dietary pattern scores and 'meat-fish' dietary pattern scores. 'Vegetables-fruit' dietary pattern scores were inversely (unstandardised regression coefficient $B=-0.60 \mathrm{mmHg}, 95 \% \mathrm{CI}-1.04,-0.16$ ) and 'snacks-drinks-milk products' dietary pattern scores were positively $(B=0.50 \mathrm{mmHg}, 95 \% \mathrm{CI} \mathrm{0.08,0.92)}$ associated with DBP in men in multiple regressions. Higher 'meat-fish' dietary pattern scores were associated with higher BMI $\left(B=0.19 \mathrm{~kg} / \mathrm{m}^{2}, 95 \% \mathrm{CI} 0 \cdot 06,0.33\right)$, waist-to-hip ratio $(B=0.004,95 \% \mathrm{CI} 0.002,0.007)$ and WC $(B=0.57 \mathrm{~cm}, 95 \% \mathrm{CI} 0 \cdot 18,0 \cdot 97)$ in men, and higher BMI $\left(B=0.40 \mathrm{~kg} / \mathrm{m}^{2}, 95 \%\right.$ CI $\left.0.22,0.57\right)$, WC $(B=0.87 \mathrm{~cm}, 95 \% \mathrm{CI} 0.39,1.36)$ and $\mathrm{HC}(B=0.61 \mathrm{~cm}, 95 \% \mathrm{CI} 0.26,0.96)$ in women in multiple regressions. The influence of demographic and lifestyle characteristics on dietary patterns and the health risks associated with dietary patterns provides insights for the provision of tangible dietary advice to this population.

Key words: Dietary patterns: Factor analysis: Cross-sectional studies: Chinese elderly

Epidemiological studies have shown that the risk of many chronic diseases varies with diet. There is a wealth of evidence suggesting that dietary behaviour is an aetiological factor in the development of obesity and chronic diseases ${ }^{(1-3)}$, and mortality from chronic diseases ${ }^{(4-7)}$. Since diet is a combination of long-term, multiple exposures of food and nutrients, this makes it difficult to identify the effects on individual dietary components on health and disease. The focus on a single nutrient or food group may be one of the reasons to account for the inconsistent results between diet and diseases ${ }^{(8,9)}$. The independent effect of a single nutrient or food group can vary depending on the food that it is derived from due to interactions between nutrients or physical characteristics of foods ${ }^{(8)}$. In addition, the degree of independent variation of the nutrients is markedly reduced when these nutrients are entered simultaneously into a model due to high intercorrelation among some nutrients ${ }^{(10)}$. As a result, this has led to increased interest in identifying dietary patterns in

Abbreviations: DBP, diastolic blood pressure; PASE, Physical Activity Scale for the Elderly; SES, socio-economic status; WC, waist circumference.

* Corresponding author: Dr Ruth Chan, fax +852 2637 9215, email ruthchansm@cuhk.edu.hk

(C) The Author(s) 2012. The online version of this article is published within an Open Access environment subject to the conditions of the Creative Commons Attribution-NonCommercial-ShareAlike licence <http://creativecommons.org/licenses/by-nc-sa/2.5/>. The written permission of 
order to understand the relationship between diet and the risk of chronic diseases.

Dietary pattern analysis has recently emerged as an alternative approach to examine the relationship between diet and the risk of disease ${ }^{(10)}$. It allows the examination of the whole diet, and dietary pattern represents a broader picture of food and nutrient consumption, and may therefore be more predictive of disease risk than individual foods or nutrients ${ }^{(9-11)}$. There has been an extensive body of literature on the dietary patterns of middle-aged adults. However, data on the dietary patterns of older people are limited ${ }^{(12-19)}$ and are seldom reported for the Chinese elderly population.

Using factor analysis, our group has identified four dietary patterns of Chinese adults in Hong Kong, namely 'more snacks and drinks', 'more vegetables, fruits and fish', 'more meat and milk products' and 'more refined grains' patterns, and found that the 'more vegetables, fruits and fish' pattern was associated with reduced risk and the 'more meat and milk products' pattern was associated with an increased risk of diabetes ${ }^{(20)}$. However, there is no information on the dietary patterns and their associations with health and diseases of Chinese older people in Hong Kong. This study therefore aimed to describe the dietary patterns of Chinese community-dwelling men and women aged 65 years and above in Hong Kong, and to examine the relationships between dietary patterns, demographics, lifestyle, anthropometry and blood pressure in this population.

\section{Subjects and methods}

\section{Subjects}

Subjects were participants of a cohort study examining the risk factors for osteoporosis in Hong $\mathrm{Kong}^{(21)}$. A total of 2000 men and 2000 women aged 65 years and above living in the community were recruited between 2001 and 2003 by placing recruitment notices in community centres for older people and in housing estates. Participants were volunteers and were able to walk or take public transport to the study site. They were recruited using a stratified sample so that approximately $33 \%$ would be in each of these age groups: 65-69, 70-74 and $75+$ years. Compared with the general population in this age group, participants had a higher educational level (12-18\% v. 3-9 \% with tertiary education in the age groups $80+, 75-79$, $70-74$ and $65-69$ years) ${ }^{(22)}$. This study was conducted according to the guidelines laid down in the Declaration of Helsinki and all procedures involving human subjects/patients were approved by the Clinical Research Ethics Committee of the Chinese University of Hong Kong. Written informed consent was obtained from all subjects. A total of 293 subjects were excluded from the analysis due to incomplete demographic, lifestyle and dietary data, and missing anthropometric and blood pressure measurements. Data on a final sample of 3707 subjects (1945 men and 1762 women) are presented in this paper.

\section{Demographic and overall health characteristics}

A standardised, structured interview was performed to collect information on age, sex, education level, self-perceived social status, smoking habits, alcohol use and medical history. Data on self-perceived socio-economic status (SES) were included since psychosocial factors are important, in addition to material conditions, for determining health ${ }^{(23,24)}$. Self-perceived SES was assessed by asking participants to place a mark on a picture of an upright ladder with ten rungs, with the lowest rung being the most undesirable and the highest the most desirable state with respect to their standing in the community (community ladder). This is a subjective measure of social status developed by the John D. and Catherine T. MacArthur Research Network on Socio-economic Status and Health, and has been associated with key health outcomes in various population surveys of different cultural and ethnic groups ${ }^{(25)}$. Participants were also asked to rate themselves by placing a mark on a picture of another ladder, the top rung representing people who have the most money, the most education and the most respected jobs, and the bottom rung representing people at the other extreme (Hong Kong ladder). The scores were dichotomised as high and low, using their median as cut-point (eight for the community ladder and five for the Hong Kong ladder).

Information on the duration and level of past and current use of cigarettes, cigars and pipes was obtained. Smoking history was classified in terms of former smoking (at least 100 cigarettes smoked in a lifetime), current smoking and never smoking. Subjects were also asked about their alcohol use, and drinking status was defined as never, former or current. Since blood pressure was one of the main outcome variables, information on the presence of hypertension and the use of anti-hypertensive medications was obtained at baseline by selfreport of their doctors' diagnoses, supplemented with the identification of drugs brought to the interviewers.

\section{Anthropometric data and blood pressure measurement}

Body weight was measured to the nearest $0 \cdot 1 \mathrm{~kg}$ with subjects wearing a light gown, using the Physician Balance Beam Scale (Healthometer). Height was measured to the nearest $0.1 \mathrm{~cm}$ using the Holtain Harpenden stadiometer (Holtain Ltd). BMI was calculated as body weight in $\mathrm{kg} /(\text { height in } \mathrm{m})^{2}$. Waist circumference (WC) was taken as the minimum circumference between the umbilicus and xiphoid processes and measured to the nearest $0.5 \mathrm{~cm}$. Hip circumference was measured as the maximum circumference around the buttocks posteriorly and the symphysis pubis anteriorly, and measured to the nearest $0.5 \mathrm{~cm}$. Waist-to-hip ratio was calculated as the waist divided by the hip circumference.

Blood pressure was measured after 5 min rest in the sitting position using a standard mercury sphygmomanometer (WA Baum Co. Inc.) by trained staff. The first and fifth Korotkoff phases were recorded as systolic blood pressure and diastolic blood pressure (DBP). The average of two readings was taken.

\section{Physical activity assessment}

Physical activity was assessed by the Physical Activity Scale for the Elderly (PASE) ${ }^{(26)}$. This is a twelve-item scale measuring the average number of hours per $\mathrm{d}$ spent in leisure, household 
and occupational physical activities over the previous 7-d period. Activity weights for each item were determined based on the amount of energy spent, and each item score was calculated by multiplying the activity weight with daily activity frequency. A composite PASE score of all the items was obtained. A higher PASE score reflects higher physical activity level.

\section{Dietary assessment and dietary pattern derivation}

Dietary intake was assessed at baseline using a validated FFQ developed in a population survey with participants aged between 25 and 74 years, the validity of which has been described elsewhere ${ }^{(27)}$. The mean nutrient quantification per day was calculated using food tables derived from McCance \& Widdowson ${ }^{(28)}$ and the Chinese Medical Sciences Institute ${ }^{(29)}$. The FFQ consisted of 280 food items. Each subject was asked to fill in the questionnaire - the food item, the size of each portion and the number of times of consumption each day and each week, using the 12 months prior to the interview as the reference period. Portion size was explained to subjects using a catalogue of pictures of individual food portions. For seasonally consumed vegetables and fruits, subjects were further asked about the months of food consumption over the past year. The amount of cooking oil was estimated according to the usual cooking methods of preparing a standardised portion of different foods. For example, $0 \cdot 5$ tablespoons of oil was estimated for $100 \mathrm{~g}$ stir-fried vegetables and 0.3 tablespoons of oil for $100 \mathrm{~g}$ steamed fish without sauce. Subjects were asked about the common cooking methods of preparing foods in the main meals. The amount of oil used was then calculated based on the usual portion of different foods consumed by the subjects.

To identify dietary patterns, individual food items from the FFQ were first aggregated into groups. A total of thirty-two separate food groups on the basis of similarity of the type of food and nutrient composition were formed. Some individual food items were preserved either because it was inappropriate to incorporate them into a certain food group (e.g. coffee, mayonnaise and tomatoes) or because they were suspected to represent distinct dietary patterns (e.g. preserved vegetables). The food groups were energy adjusted by dividing the energy intake from each food group by the total energy intake and multiplying by 100 , and were expressed as the percentage contribution to total energy ${ }^{(11)}$. Factor analysis was conducted with varimax rotation using the thirty-two food groups ${ }^{(10)}$. Factors were retained based on eigenvalues greater than $1 \cdot 0$, a scree plot and interpretability ${ }^{(30)}$. The factor scores for each pattern were calculated for each subject by summing the intakes of food items weighted by their factor loadings. A higher score indicated greater conformity with the pattern being calculated.

\section{Statistical analysis}

Statistical analyses were performed using the statistical package SPSS version 16.0 (SPSS Inc.). Logarithmic transformation was applied to improve normality whenever appropriate. A test conducted for the interaction between each dietary pattern score and sex by linear regression indicated that the effect of dietary patterns on some health parameters was significantly modified by sex; therefore, the results are presented separately for men and women. Pearson's correlation was used to examine the correlation between each dietary pattern score and intake of different nutrients. Multiple regression was used to identify factors including demographics and lifestyle variables associated with each dietary pattern score, and to examine the association between each dietary pattern score and anthropometry and blood pressure with adjustment for age (years), PASE, daily energy intake (kJ), education level (no education, primary school, secondary school/matriculation and university or above), Hong Kong ladder ( $<5 v . \geq 5$ ), community ladder $(<8 v . \geq 8)$, alcohol use (never, past and current) and smoking status (never, past and current). The multiple regression model between each dietary pattern score and blood pressure was further adjusted for BMI $\left(\mathrm{kg} / \mathrm{m}^{2}\right)$, self-reported history of hypertension (no $v$. yes), and the use of anti-hypertensive medications (no $v$. yes). An $\alpha$ level of $5 \%$ was used as the level of significance.

\section{Results}

\section{Dietary patterns in the study population}

Factor analysis identified three dietary patterns of the study population (Table 1). The first factor (vegetables-fruits pattern) that explained the greatest variance in the dietary data was dominated by a frequent intake of vegetables, fruits, legumes, soya and soya products. The second factor (snacks-drinks-milk products pattern) was characterised by a frequent intake of condiments, coffee, fast food, French fries, potato chips, nuts and milk products. The third factor (meat-fish pattern) included a frequent intake of dim sum, red and processed meats, poultry, fish and seafood.

In both men and women, total energy intake was weakly positively associated with each dietary pattern score. Similar associations of each dietary pattern score with nutrient intakes were observed in men and women (Table 2). 'Vegetablesfruits' dietary pattern scores were weakly inversely associated with saturated fat, monounsaturated fat and polyunsaturated fat intakes, and weakly positively associated with intakes of carbohydrates, protein and cholesterol. In contrast, 'vegetables-fruits' dietary pattern scores were strongly positively associated with intakes of fibre and vitamins A, C and K and were moderately positively associated with intakes of isoflavones and most micronutrients. 'Snacks-drinks-milk products' dietary pattern scores were weakly inversely associated with intakes of polyunsaturated fat and vitamin $\mathrm{K}$, and weakly positively associated with intakes of carbohydrates, protein, total fat, saturated fat, monounsaturated fat, cholesterol and vitamin D. While 'snacks-drinks-milk products' dietary pattern scores were also positively associated with intakes of fibre, most minerals and isoflavones, the associations were less strong than those with 'vegetables-fruits' dietary pattern scores. 'Meat-fish' dietary pattern scores were weakly positively associated with intakes of polyunsaturated fat and 
Table 1. Food group factor loadings for the three dietary patterns

\begin{tabular}{|c|c|c|c|}
\hline \multirow[b]{2}{*}{ Food groups } & \multicolumn{3}{|c|}{ Dietary patterns } \\
\hline & $\begin{array}{l}\text { Factor 1: } \\
\text { vegetables- } \\
\text { fruits }\end{array}$ & $\begin{array}{l}\text { Factor 2: snacks- } \\
\text { drinks-milk } \\
\text { products }\end{array}$ & $\begin{array}{l}\text { Factor 3: } \\
\text { meat-fish }\end{array}$ \\
\hline Other vegetables & $0.58^{*}$ & -0.06 & 0.02 \\
\hline Tomatoes & $0.49^{\star}$ & 0.03 & -0.01 \\
\hline $\begin{array}{l}\text { Dark green and } \\
\text { leafy vegetables }\end{array}$ & $0.43^{\star}$ & -0.26 & -0.02 \\
\hline $\begin{array}{l}\text { Cruciferous } \\
\text { vegetables }\end{array}$ & $0.43^{*}$ & -0.05 & -0.06 \\
\hline Starchy vegetables & $0.42^{*}$ & 0.03 & 0.00 \\
\hline Soya & $0.42^{*}$ & 0.08 & 0.11 \\
\hline Fruits & $0.40^{\star}$ & 0.03 & -0.01 \\
\hline Legumes & $0.34^{*}$ & -0.01 & 0.02 \\
\hline $\begin{array}{l}\text { Mushrooms and } \\
\text { fungi }\end{array}$ & $0.22^{*}$ & 0.06 & -0.07 \\
\hline Fats and oils & $-0.37^{\star}$ & -0.21 & 0.15 \\
\hline Condiments & -0.05 & $0.48^{\star}$ & -0.13 \\
\hline Coffee & -0.15 & $0.42^{*}$ & -0.17 \\
\hline Fast food & -0.03 & $0.37^{\star}$ & 0.04 \\
\hline Nuts & 0.12 & $0.37^{\star}$ & -0.03 \\
\hline $\begin{array}{l}\text { French fries and } \\
\text { potato chips }\end{array}$ & -0.03 & $0.37^{*}$ & 0.09 \\
\hline $\begin{array}{l}\text { Milk and milk } \\
\text { products }\end{array}$ & 0.08 & $0.31^{*}$ & -0.14 \\
\hline Whole grains & 0.14 & $0.30^{*}$ & -0.17 \\
\hline $\begin{array}{l}\text { Sweets and } \\
\text { desserts }\end{array}$ & 0.02 & $0.29^{*}$ & 0.08 \\
\hline Beverages & -0.03 & $0.22^{*}$ & 0.09 \\
\hline Dim sum & -0.17 & -0.11 & $0.56^{\star}$ \\
\hline $\begin{array}{l}\text { Red and } \\
\text { processed } \\
\text { meats }\end{array}$ & -0.07 & 0.06 & $0.46^{\star}$ \\
\hline Poultry & 0.06 & 0.11 & $0.45^{\star}$ \\
\hline Fish and seafood & 0.22 & -0.17 & $0.37^{*}$ \\
\hline Wine & -0.14 & $0 \cdot 10$ & $0.20^{\star}$ \\
\hline Refined grains & -0.25 & -0.50 & $-0.69^{\star}$ \\
\hline $\begin{array}{l}\text { Cakes, cookies, } \\
\text { pies and biscuits }\end{array}$ & 0.06 & 0.14 & 0.19 \\
\hline Eggs & 0.07 & 0.19 & 0.05 \\
\hline Organ meats & -0.08 & 0.15 & 0.12 \\
\hline Others & 0.01 & 0.07 & 0.03 \\
\hline $\begin{array}{l}\text { Preserved } \\
\quad \text { vegetables }\end{array}$ & -0.02 & 0.08 & 0.00 \\
\hline Soups & 0.00 & 0.00 & -0.01 \\
\hline Tea & 0.00 & 0.15 & 0.03 \\
\hline $\begin{array}{r}\% \text { Variance } \\
\text { explained }\end{array}$ & $6 \cdot 2$ & 5.4 & $5 \cdot 1$ \\
\hline
\end{tabular}

${ }^{*}$ Factor loadings with an absolute value $\geq 0.2$. For food groups that load more than one dietary pattern, only the highest absolute value of loading is shown.

most micronutrients, moderately positively associated with intakes of protein, total fat and monounsaturated fat and were strongly positively associated with saturated fat and cholesterol intakes. The positive associations of protein, total fat and different kinds of fat and cholesterol with 'meatfish' dietary pattern scores were stronger than those with 'snacks-drinks-milk products' dietary pattern scores.

\section{Participants' characteristics by dietary pattern scores}

Mean age did not differ significantly between men (72.3 (SD $5 \cdot 0)$ years) and women $(72 \cdot 4$ (SD 5.2) years). There were significant sex differences in PASE, energy intake, self-perceived SES, education, smoking status and alcohol use (data not shown). Results of the multiple regression analyses examining the specific predictors for each dietary pattern score in men and women are shown in Tables 3 and 4, respectively. In men, 'vegetables-fruits' dietary pattern scores were significantly positively associated with age, PASE score, energy intake and education level. Men who were never-drinkers and never-smokers were also associated with higher 'vegetables-fruits' dietary pattern scores. Men who had higher energy intake, higher education level and higher scoring in the Hong Kong ladder and who were current drinkers and smokers were significantly associated with higher 'snacksdrinks-milk products' dietary pattern scores. Men who had higher energy intake, received no education, and reported to be current drinkers were significantly associated with higher 'meat-fish' dietary pattern scores.

In women, 'vegetables-fruits' dietary pattern scores were significantly positively associated with PASE score, energy intake, education of primary and secondary school levels, higher selfperceived social status (community ladder), and being neverdrinker and never-smoker. Women who had higher energy intake, higher education level and higher scoring in the Hong Kong ladder and reported to be current drinkers and current smokers were significantly associated with higher 'snacksdrinks-milk products' dietary pattern scores. Women who had a lower PASE score and higher energy intake were significantly associated with higher 'meat-fish' dietary pattern scores.

\section{Associations between dietary pattern scores, anthropometry and blood pressure}

Table 5 shows the multiple regression coefficients linking anthropometry and blood pressure to each dietary pattern score in both sexes. 'Vegetables-fruits' dietary pattern scores were significantly positively associated with BMI and inversely associated with DBP in men, and were inversely associated with WC in women in adjusted models. In men, 'snacksdrinks-milk products' dietary pattern scores were significantly inversely associated with waist-to-hip ratio and positively associated with DBP in adjusted models. In contrast, none of the health parameters was associated with 'snacksdrinks-milk products' dietary pattern scores in women in adjusted models. Higher 'meat-fish' dietary pattern scores were significantly associated with higher BMI, waist-to-hip ratio and WC in men and higher BMI, WC and hip circumference in women in adjusted models.

\section{Discussion}

In this study, we identified three dietary patterns using factor analysis, namely 'vegetables-fruits', 'snacks-drinks-milk products' and 'meat-fish'. This study also indicated the influence of demographic, socio-economic and lifestyle characteristics on dietary patterns, and suggested associations between different dietary patterns and health parameters.

Previous studies conducted in the Caucasian elderly population mostly identified two to three dietary patterns ${ }^{(13,16,18,19,31-33)}$. Most of them called a relatively more healthy dietary pattern 'prudent', 'high nutrient-dense', or 


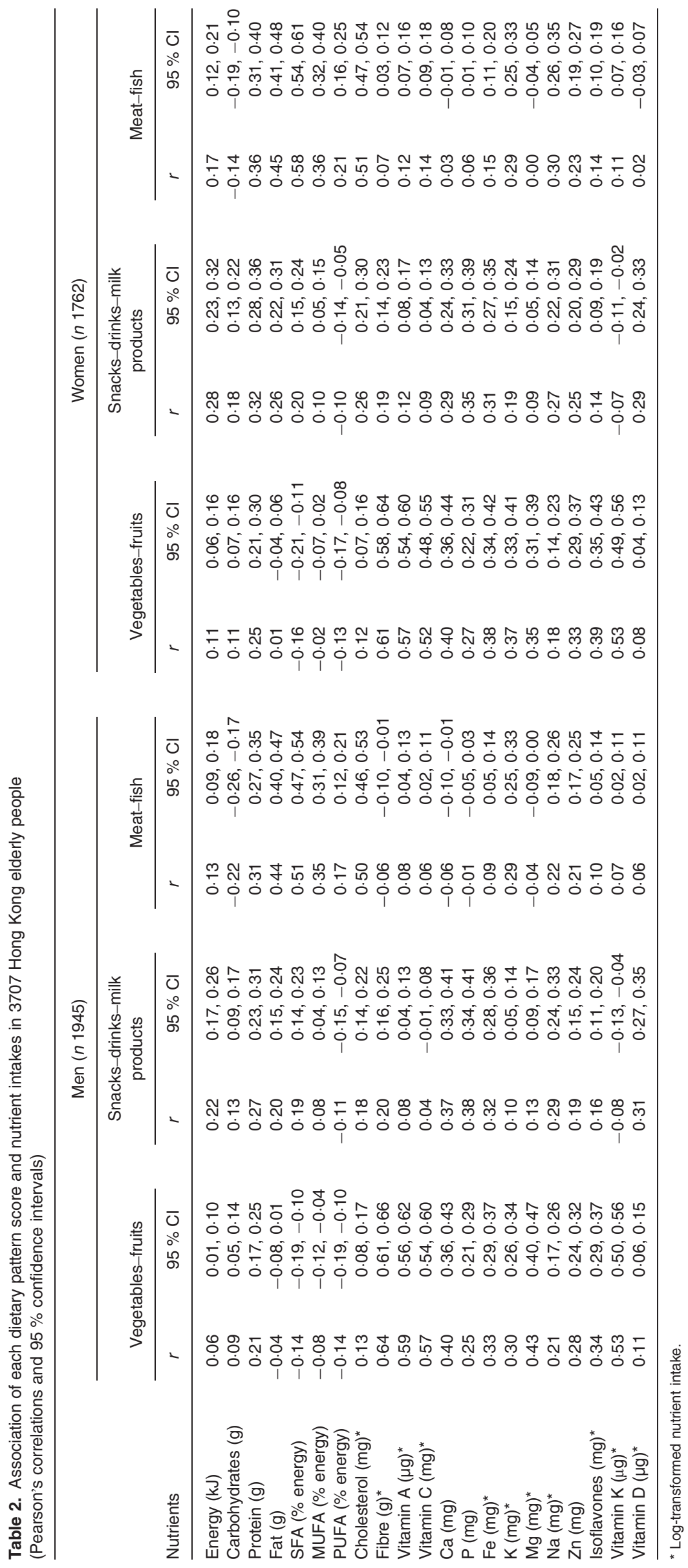


Table 3. Multiple regression analyses examining specific predictors for each dietary pattern score in 1945 Hong Kong elderly men (Regression coefficients and $95 \%$ confidence intervals)

\begin{tabular}{|c|c|c|c|c|c|c|}
\hline \multirow[b]{2}{*}{ Characteristics } & \multicolumn{2}{|c|}{ Vegetables-fruits } & \multicolumn{2}{|c|}{ Snacks-drinks-milk products } & \multicolumn{2}{|c|}{ Meat-fish } \\
\hline & $B^{*}$ & $95 \% \mathrm{Cl}$ & $B^{\star}$ & $95 \% \mathrm{Cl}$ & $B^{\star}$ & $95 \% \mathrm{Cl}$ \\
\hline Age (years) (per 1 sD increment) & 0.048 & $0.006,0.090$ & -0.002 & $-0.046,0.042$ & 0.031 & $-0.016,0.078$ \\
\hline PASE (per 1 sD increment) & 0.086 & $0.045,0.127$ & 0.009 & $-0.035,0.052$ & -0.019 & $-0.065,0.027$ \\
\hline Energy intake (kJ) (per 1 SD increment) & 0.163 & $0.016,0.309$ & 0.669 & $0.515,0.823$ & 0.477 & $0.312,0.641$ \\
\hline \multicolumn{7}{|l|}{ Education } \\
\hline \multicolumn{7}{|l|}{ No education (reference) } \\
\hline Primary school & 0.057 & $-0.133,0.248$ & 0.169 & $-0.031,0.370$ & -0.258 & $-0.471,-0.044$ \\
\hline Secondary school/matriculation & 0.192 & $-0.008,0.393$ & 0.501 & $0.290,0.712$ & -0.318 & $-0.543,-0.094$ \\
\hline University or above & 0.365 & $0.148,0.582$ & 0.943 & $0.715,1.171$ & -0.550 & $-0.793,-0.307$ \\
\hline \multicolumn{7}{|l|}{$\begin{array}{l}\text { Hong Kong ladder } \\
<5 \text { (reference) }\end{array}$} \\
\hline$\geq 5$ & -0.034 & $-0.121,0.052$ & 0.131 & $0.040,0.222$ & 0.081 & $-0.015,0.178$ \\
\hline \multicolumn{7}{|l|}{$\begin{array}{l}\text { Community ladder } \\
<8 \text { (reference) }\end{array}$} \\
\hline$\geq 8$ & 0.036 & $-0.052,0.125$ & 0.049 & $-0.044,0.142$ & 0.077 & $-0.023,0.176$ \\
\hline \multicolumn{7}{|l|}{ Alcohol use } \\
\hline \multicolumn{7}{|l|}{ Never (reference) } \\
\hline Past & 0.094 & $-0.122,0.309$ & 0.027 & $-0.199,0.253$ & 0.162 & $-0.079,0.403$ \\
\hline Current & -0.123 & $-0.220,-0.025$ & 0.173 & $0.071,0.276$ & 0.344 & $0.235,0.453$ \\
\hline \multicolumn{7}{|l|}{ Smoking status } \\
\hline Never (reference) & & & & & & \\
\hline Past & -0.099 & $-0.188,-0.009$ & -0.002 & $-0.096,0.092$ & 0.002 & $-0.098,0.102$ \\
\hline Current & -0.432 & $-0.570,-0.293$ & 0.153 & $0.007,0.299$ & 0.135 & $-0.021,0.290$ \\
\hline
\end{tabular}

PASE, Physical Activity Scale for the Elderly.

* The multiple linear regression model was adjusted for age, energy intake, PASE, education level, Hong Kong ladder, community ladder, smoking status and alcohol use.

'Mediterranean-style' and used 'Western', 'low nutrient-dense' and 'sweet and fat' for a less healthy pattern ${ }^{(14,16,18,19)}$. As dietary patterns are culturally determined, comparing dietary patterns of the Chinese population with those of the Caucasian population is difficult. In contrast, the dietary patterns identified in the present study were close to those previously reported for the Chinese population. A 'meat-dim sum' dietary pattern and a 'vegetable-fruit-soy' dietary pattern were

Table 4. Multiple regression analyses examining specific predictors for each dietary pattern score in 1762 Hong Kong elderly women (Regression coefficients and $95 \%$ confidence intervals)

\begin{tabular}{|c|c|c|c|c|c|c|}
\hline \multirow[b]{2}{*}{ Characteristics } & \multicolumn{2}{|c|}{ Vegetables-fruits } & \multicolumn{2}{|c|}{$\begin{array}{l}\text { Snacks-drinks-milk } \\
\text { products }\end{array}$} & \multicolumn{2}{|c|}{ Meat-fish } \\
\hline & $B^{\star}$ & $95 \% \mathrm{Cl}$ & $B^{\star}$ & $95 \% \mathrm{Cl}$ & $B^{\star}$ & $95 \% \mathrm{Cl}$ \\
\hline Age (years) (per 1 sD increment) & 0.008 & $-0.044,0.059$ & 0.005 & $-0.039,0.050$ & -0.032 & $-0.078,0.014$ \\
\hline PASE (per 1 sD increment) & 0.048 & $-0.001,0.097$ & 0.011 & $-0.031,0.054$ & -0.064 & $-0.107,-0.020$ \\
\hline Energy intake (kJ) (per 1 SD increment) & 0.333 & $0.167,0.499$ & 0.755 & $0.611,0.899$ & 0.525 & $0.376,0.674$ \\
\hline \multicolumn{7}{|l|}{$\begin{array}{l}\text { Education } \\
\quad \text { No education (reference) }\end{array}$} \\
\hline Primary school & 0.112 & $0.006,0.219$ & 0.119 & $0.026,0.211$ & 0.028 & $-0.068,0.123$ \\
\hline Secondary school/matriculation & 0.361 & $0.198,0.524$ & 0.492 & $0.351,0.634$ & -0.011 & $-0.158,0.135$ \\
\hline University or above & 0.173 & $-0.036,0.382$ & 0.904 & $0.733,1.085$ & 0.102 & $-0.086,0.289$ \\
\hline \multicolumn{7}{|l|}{$\begin{array}{l}\text { Hong Kong ladder } \\
<5 \text { (reference) }\end{array}$} \\
\hline$\geq 5$ & -0.001 & $-0.102,0.100$ & 0.093 & $0.005,0.181$ & 0.086 & $-0.005,0.177$ \\
\hline \multicolumn{7}{|l|}{$\begin{array}{l}\text { Community ladder } \\
<8 \text { (reference) }\end{array}$} \\
\hline$\geq 8$ & 0.112 & $0.015,0.210$ & 0.039 & $-0.045,0.124$ & -0.031 & $-0.118,0.056$ \\
\hline \multicolumn{7}{|l|}{ Alcohol use } \\
\hline Current & 0.325 & $-0.629,-0.020$ & 0.337 & $0.073,0.601$ & 0.140 & $-0.133,0.413$ \\
\hline \multicolumn{7}{|l|}{$\begin{array}{l}\text { Smoking status } \\
\text { Never (reference) }\end{array}$} \\
\hline Past & 0.187 & $-0.368,-0.005$ & 0.064 & $-0.093,0.222$ & 0.044 & $-0.119,0.206$ \\
\hline Current & 0.496 & $-0.874,-0.118$ & 0.456 & $0.129,0.784$ & 0.048 & $-0.291,0.387$ \\
\hline
\end{tabular}

PASE, Physical Activity Scale for the Elderly.

* Multiple linear regression model was adjusted for age, energy intake, PASE, education level, Hong Kong ladder, community ladder, smoking status and alcohol use.

† Due to the limited number of subjects with past alcohol use, the 'Never' and 'Past' categories were combined. 


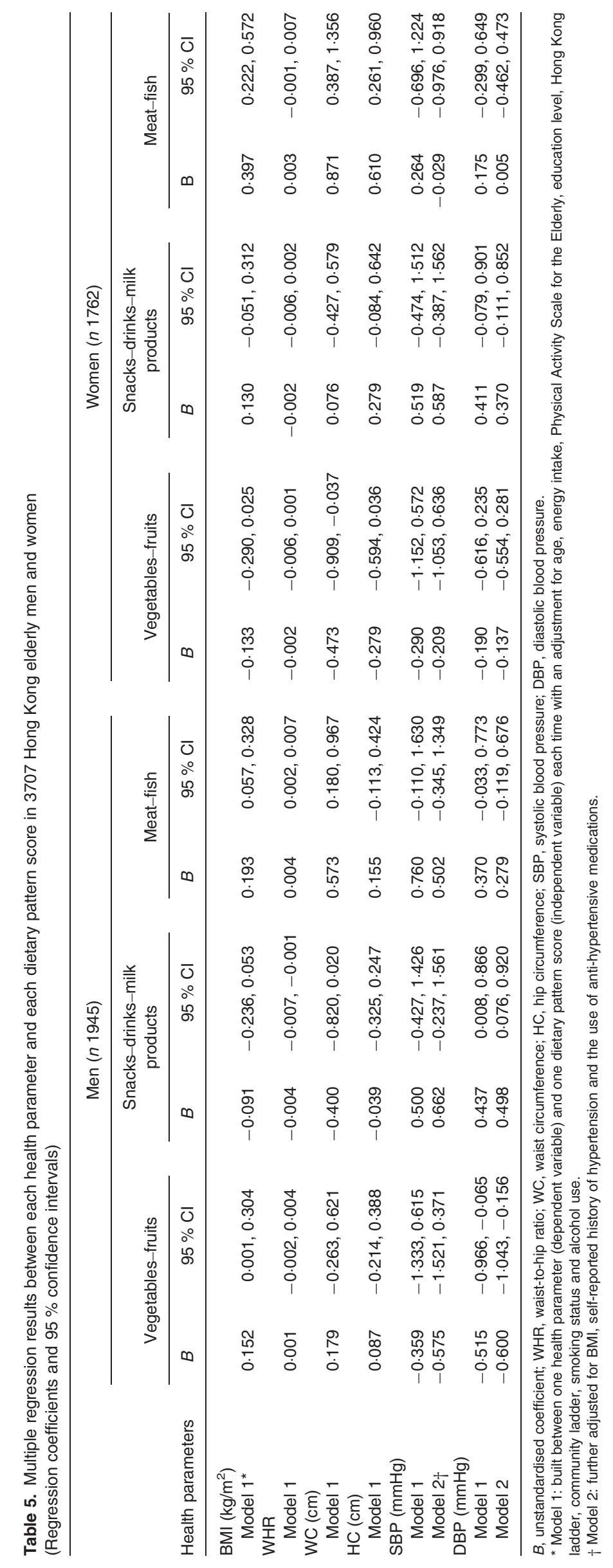


identified in a population-based prospective study of 61321 Singapore Chinese examining the association between dietary patterns and colorectal cancer risk ${ }^{(34)}$. The dietary patterns identified in our elderly population were also similar to those identified in Chinese adults in Hong Kong, namely 'more snacks and drinks', 'more vegetables, fruits and fish', 'more meat and milk products' and 'more refined grains' patterns ${ }^{(20)}$. The fact that diet habits differ across countries may be one reason for the different dietary patterns identified in various studies. The way to handle the food intake data in dietary pattern analysis may be another reason. While some studies used individual food items for dietary pattern analysis, others aggregated food items into food groups based on similar nutrient profiles to minimise the number of variables considered and reduce the within-person variation in the consumption of individual foods ${ }^{(33)}$. In addition, the results may differ depending on the dietary pattern methods used ${ }^{(11)}$ and whether the food groups were energy adjusted for dietary pattern analysis ${ }^{(35,36)}$.

Our study confirmed previous studies that reported that dietary patterns were correlated with lifestyle factors and SES. In our study, participants with a less healthy lifestyle (i.e. less physically active, being a current smoker and a current drinker) were more likely to have a 'snacks-drinks-milk products' dietary pattern and a 'meat-fish' dietary pattern. These findings were consistent with the findings of previous studies $^{(13,15,16,31-34)}$. Individuals with a relatively more healthy dietary pattern are prone to be more physically active ${ }^{(16,31-33)}$. Other studies also showed that smoking status and alcohol use were associated with a less healthy dietary pattern ${ }^{(15,34)}$. Several studies have examined the relationship between dietary patterns and SES; however, the results were inconclusive ${ }^{(13,14,16,31,34)}$. Most studies used the objective measures of SES only. Our study included both the objective and subjective measures of SES. Multiple regression analyses in the present study suggested that education level (the objective measure) was related to dietary patterns in both men and women. In addition, higher rating of the Hong Kong ladder (the subjective measure) was associated with higher 'snacksdrinks-milk products' dietary pattern scores in both sexes. In contrast, a positive association of the community ladder (the subjective measure) with the 'vegetables-fruits' dietary pattern score was only observed in women. The Hong Kong ladder is more related to occupation, education and income. The consistent associations between education level and dietary patterns as well as the positive associations between the Hong Kong ladder and selected dietary patterns in this study therefore suggested that dietary patterns may be more closely related to occupation, education and income than social ranking per se. Our findings are compatible with observations from other studies, showing that lower SES was associated with relatively less healthy dietary patterns ${ }^{(13,16,31)}$. A healthy lifestyle may also be more related to knowledge, and the ability to act on the knowledge, of a healthy lifestyle as a result of better education and income ${ }^{(24)}$.

Our study showed that DBP was inversely associated with 'vegetables-fruit' dietary pattern scores and positively associated with 'snacks-drinks-milk products' dietary pattern scores in men. Similar associations were observed in women although the associations were not significant. The inverse association observed between 'vegetables-fruit' dietary pattern scores and DBP is consistent with other investigations examining the relationship of dietary patterns and the risk of hypertension or blood pressure ${ }^{(37,38)}$. A cross-sectional analysis of dietary patterns and the metabolic syndrome in 773 elderly subjects from the Adventist Health Study revealed that a vegetarian dietary pattern was associated with a more favourable profile of metabolic risk factors including blood pressure and a lower risk of the metabolic syndrome when compared with a nonvegetarian dietary pattern ${ }^{(37)}$. In a clinical trial that investigated the effect of a diet rich in fruits, vegetables, low-fat dairy products with reduced saturated and total fat in 459 adults with an average systolic blood pressure of less than $160 \mathrm{mmHg}$ and a DBP of $80-95 \mathrm{mmHg}$ in the USA, such a diet reduced the systolic blood pressure and DBP by 5.5 and $3.0 \mathrm{mmHg}$, respectively, compared with a control typical US diet ${ }^{(39)}$.

Several biological mechanisms may explain the beneficial effects of a 'vegetables-fruit' dietary pattern on blood pressure. It is suggested that flavonoids in vegetables, fruits and legumes exhibit cardioprotective properties, including anti-oxidant and anti-inflammatory effects and induction of apoptosis ${ }^{(40)}$. Moreover, the 'vegetables-fruit' dietary pattern was characterised by rich sources of $\mathrm{Mg}$, $\mathrm{Ca}$ and $\mathrm{K}$. Clinical and epidemiological studies have suggested that these nutrients have vasodilation properties and thus may reduce blood pressure $^{(41-43)}$. In contrast, the positive association between 'snacks-drinks-milk products' dietary pattern scores and DBP in men was less easy to interpret since this pattern is composed of healthy and unhealthy food groups. In comparison with the 'vegetables-fruit' dietary pattern, the positive association of this pattern with intake of fibre, most minerals and isoflavones was less strong. These findings may partly explain the positive association between 'snacks-drinks-milk products' dietary pattern scores and DBP in men in the present study.

Our study showed that the 'meat-fish' dietary pattern had the greatest influence on obesity indices in elderly men and women compared with the other dietary patterns. Some studies did not find any association between BMI and dietary patterns $^{(13,31)}$, while others showed mixed associations ${ }^{(32,33)}$. The 'meat-fish' dietary pattern identified in the present study was characterised by a high intake of dim sum, meat, fish, seafood, wine, protein, fat and cholesterol and a low intake of vegetables, fruits and fibre. Epidemiological evidence generally suggested that such a dietary pattern that was relatively high in animal foods, total fat and saturated fat and low in plant foods and fibre was associated with a greater risk of abdominal obesity ${ }^{(44)}$, greater gains in BMI and $\mathrm{WC}^{(45)}$, and a less favourable biomarker profile for obesity and cardiovascular risk ${ }^{(46)}$.

In recent decades, one of the main problems faced by the ageing population in Hong Kong is the disease and disability burden from non-communicable diseases such as hypertension and stroke ${ }^{(47)}$. Our study and other investigations have shown that a diet rich in vegetables and fruits could possibly help reduce blood pressure and the risk of hypertension. Moreover, our data suggested that a diet dominated by 
frequent intake of dim sum and meat increased the risk of obesity. The influence of demographic and lifestyle characteristics on the dietary patterns observed in this study also provides insights for the provision of tangible dietary advice to Chinese community-dwelling older people in Hong Kong. For example, less healthy dietary patterns are more common amongst older people of lower education level; this has implications for health promotion in this target group. Our findings also highlight the importance of considering variations in physical activity level, smoking behaviour and alcohol use while addressing the quality of the diets of older people.

The strengths of our study included a large population of older men and women living in the community and the inclusion of the subjective measures of SES. However, our study had several limitations. First, our study was crosssectional in nature, and thus the causal relationship between dietary patterns and various health parameters could not be determined. Second, a common criticism of dietary pattern analysis is that collapsing the primary data into a smaller number of items is an inherently subjective procedure ${ }^{(48)}$. To overcome this problem we followed widely accepted rules for choosing the number of factors to be retained ${ }^{(30)}$. Third, our sample was of a higher educational standard compared with the general Hong Kong population. Therefore, the results may not be generalised to the general population.

In conclusion, our study identified three dietary patterns of Chinese community-dwelling older people in Hong Kong, namely 'vegetables-fruits', 'snacks-drinks-milk products' and 'meat-fish'. Individuals with a less healthy lifestyle and of lower SES were more likely to have less favourable dietary patterns, and this may possibly lead to higher DBP and a greater risk of obesity. The influence of demographic, socio-economic and lifestyle characteristics on dietary patterns in this study provides insights for the provision of tangible dietary advice to Chinese community-dwelling older people in Hong Kong.

\section{Acknowledgements}

We would like to thank Ms Kay Yuen for the coordination of this study. This study was supported by grants from the Research Grants Council of Hong Kong, CUHK 4101/ 02M; the Hong Kong Jockey Club Charities Trust; the SH Ho Centre for Gerontology and Geriatrics and the Centre for Nutritional Studies, The Chinese University of Hong Kong. R. C. conducted the statistical analyses and wrote the manuscript. J. W. conceptualised the study design, supervised the study and assisted in manuscript preparation. D. C. assisted in the statistical analyses and manuscript preparation. None of the authors has any personal or financial conflict of interest to declare.

\section{References}

1. Hu FB, Rimm EB, Stampfer MJ, et al. (2000) Prospective study of major dietary patterns and risk of coronary heart disease in men. Am J Clin Nutr 72, 912-921.

2. Schroder H (2007) Protective mechanisms of the Mediterranean diet in obesity and type 2 diabetes. J Nutr Biochem 18, 149-160.
3. Manios Y, Kourlaba G, Grammatikaki E, et al. (2010) Development of a diet-lifestyle quality index for young children and its relation to obesity: the preschoolers diet-lifestyle index. Public Health Nutr 13, 2000-2009.

4. Osler M, Heitmann BL, Gerdes LU, et al. (2001) Dietary patterns and mortality in Danish men and women: a prospective observational study. Br J Nutr 85, 219-225.

5. Lockheart MS, Steffen LM, Rebnord HM, et al. (2007) Dietary patterns, food groups and myocardial infarction: a case-control study. Br J Nutr 98, 380-387.

6. Shimazu T, Kuriyama S, Hozawa A, et al. (2007) Dietary patterns and cardiovascular disease mortality in Japan: a prospective cohort study. Int J Epidemiol 36, 600-609.

7. Brunner EJ, Mosdol A, Witte DR, et al. (2008) Dietary patterns and 15-y risks of major coronary events, diabetes, and mortality. Am J Clin Nutr 87, 1414-1421.

8. van Dam RM (2005) New approaches to the study of dietary patterns. Br J Nutr 93, 573-574.

9. Slattery ML (2008) Defining dietary consumption: is the sum greater than its parts? Am J Clin Nutr 88, 14-15.

10. Hu FB (2002) Dietary pattern analysis: a new direction in nutritional epidemiology. Curr Opin Lipidol 13, 3-9.

11. Reedy J, Wirfalt E, Flood A, et al. (2010) Comparing 3 dietary pattern methods-cluster analysis, factor analysis, and index analysiswith colorectal cancer risk: the NIH-AARP diet and health study. Am J Epidemiol 171, 479-487.

12. Pala V, Sieri S, Masala G, et al. (2006) Associations between dietary pattern and lifestyle, anthropometry and other health indicators in the elderly participants of the EPIC-Italy cohort. Nutr Metab Cardiovasc Dis 16, 186-201.

13. Robinson S, Syddall H, Jameson K, et al. (2009) Current patterns of diet in community-dwelling older men and women: results from the Hertfordshire Cohort Study. Age Ageing 38, 594-599.

14. Hamer M, McNaughton SA, Bates CJ, et al. (2010) Dietary patterns, assessed from a weighed food record, and survival among elderly participants from the United Kingdom. Eur J Clin Nutr 64, 853-861.

15. Masala G, Ceroti M, Pala V, et al. (2007) A dietary pattern rich in olive oil and raw vegetables is associated with lower mortality in Italian elderly subjects. Br J Nutr 98, 406-415.

16. Waijers PM, Ocke MC, van Rossum CT, et al. (2006) Dietary patterns and survival in older Dutch women. Am J Clin Nutr 83, 1170-1176.

17. Bamia C, Trichopoulos D, Ferrari P, et al. (2007) Dietary patterns and survival of older Europeans: the EPIC-Elderly Study (European Prospective Investigation into Cancer and Nutrition). Public Health Nutr 10, 590-598.

18. Konstantinova SV, Tell GS, Vollset SE, et al. (2008) Dietary patterns, food groups, and nutrients as predictors of plasma choline and betaine in middle-aged and elderly men and women. $A m \mathrm{~J}$ Clin Nutr 88, 1663-1669.

19. Ledikwe JH, Smiciklas-Wright H, Mitchell DC, et al. (2004) Dietary patterns of rural older adults are associated with weight and nutritional status. J Am Geriatr Soc 52, 589-595.

20. Yu R, Woo J, Chan R, et al. (2011) Relationship between dietary intake and the development of type 2 diabetes in a Chinese population: the Hong Kong dietary survey. Public Health Nutr 14, 1133 1141.

21. Wong SY, Kwok T, Woo J, et al. (2005) Bone mineral density and the risk of peripheral arterial disease in men and women: results from Mr. and Ms Os, Hong Kong. Osteoporos Int 16, 1933-1938.

22. Census and Statistics Department (2006) Hong Kong 2006 Population By-census Thematic Report: Older Persons. Hong Kong: Census and Statistics Department.

23. Marmot M \& Wilkinson RG (2001) Psychosocial and material pathways in the relation between income and health: a response to Lynch et al. Br Med J 322, 1233-1236.

24. Woo J, Lynn H, Leung J, et al. (2008) Self-perceived social status and health in older Hong Kong Chinese women compared with men. Women Health 48, 209-234. 
25. Adler NE, Epel ES, Castellazzo G, et al. (2000) Relationship of subjective and objective social status with psychological and physiological functioning: preliminary data in healthy white women. Health Psychol 19, 586-592.

26. Washburn RA, Smith KW, Jette AM, et al. (1993) The Physical Activity Scale for the Elderly (PASE): development and evaluation. J Clin Epidemiol 46, 153-162.

27. Woo J, Leung SSF, Ho SC, et al. (1997) A food frequency questionnaire for use in the Chinese population in Hong Kong: description and examination of validity. Nutr Res 17, 1633-1641.

28. Paul AA \& Southgate DAT (1978) McCance and Widdonson's: The Composition of Foods, 4th ed. London: HMSO.

29. Yang Y, Wang G \& Pan X (2002) China Food Composition 2002. Peking: University Medical Press.

30. Field A (2005) Discovering Statistics Using SPSS. London: Sage Publications.

31. Butler LM, Wu AH, Wang R, et al. (2010) A vegetable-fruit-soy dietary pattern protects against breast cancer among postmenopausal Singapore Chinese women. Am J Clin Nutr 91, 1013-1019.

32. Bamia C, Orfanos P, Ferrari P, et al. (2005) Dietary patterns among older Europeans: the EPIC-Elderly study. Br J Nutr 94, 100-113.

33. Cai H, Zheng W, Xiang YB, et al. (2007) Dietary patterns and their correlates among middle-aged and elderly Chinese men: a report from the Shanghai Men's Health Study. Br J Nutr 98, 1006-1013.

34. Butler LM, Wang R, Koh WP, et al. (2008) Prospective study of dietary patterns and colorectal cancer among Singapore Chinese. Br J Cancer 99, 1511-1516.

35. Northstone K, Ness AR, Emmett PM, et al. (2008) Adjusting for energy intake in dietary pattern investigations using principal components analysis. Eur J Clin Nutr 62, 931-938.

36. Hearty AP \& Gibney MJ (2009) Comparison of cluster and principal component analysis techniques to derive dietary patterns in Irish adults. Br J Nutr 101, 598-608.

37. Rizzo NS, Sabate J, Jaceldo-Siegl K, et al. (2011) Vegetarian dietary patterns are associated with a lower risk of metabolic syndrome: the Adventist Health Study 2. Diabetes Care 34, 1225-1227.
38. Nunez-Cordoba JM, Alonso A, Beunza JJ, et al. (2009) Role of vegetables and fruits in Mediterranean diets to prevent hypertension. Eur J Clin Nutr 63, 605-612.

39. Appel LJ, Moore TJ, Obarzanek E, et al. (1997) A clinical trial of the effects of dietary patterns on blood pressure. DASH collaborative research group. $N$ Engl J Med 336, 1117-1124.

40. Erdman JWJ, Balentine D, Arab L, et al. (2005) Flavonoids and heart health: Proceedings of the ILSI North America Flavonoids Workshop, 31 May-1 June 2005, Washington, DC. J Nutr 137, S718-S737.

41. Burgess E, Lewanczuk R, Bolli P, et al. (1999) Lifestyle modifications to prevent and control hypertension. 6. Recommendations on potassium, magnesium and calcium. Canadian Hypertension Society, Canadian Coalition for High Blood Pressure Prevention and Control, Laboratory Centre for Disease Control at Health Canada, Heart and Stroke Foundation of Canada. Can Med Assoc J 160, S35-S45.

42. Cappuccio FP, Elliott P, Allender PS, et al. (1995) Epidemiologic association between dietary calcium intake and blood pressure: a meta-analysis of published data. Am J Epidemiol 142, 935-945.

43. Mizushima S, Cappuccio FP, Nichols R, et al. (1998) Dietary magnesium intake and blood pressure: a qualitative overview of the observational studies. J Hum Hypertens 12, 447-453.

44. Dugee O, Khor GL, Lye MS, et al. (2009) Association of major dietary patterns with obesity risk among Mongolian men and women. Asia Pac J Clin Nutr 18, 433-440.

45. Newby PK, Muller D, Hallfrisch J, et al. (2003) Dietary patterns and changes in body mass index and waist circumference in adults. $\mathrm{Am} \mathrm{J}$ Clin Nutr 77, 1417-1425.

46. Fung TT, Rimm EB, Spiegelman D, et al. (2001) Association between dietary patterns and plasma biomarkers of obesity and cardiovascular disease risk. Am J Clin Nutr 73, 61-67.

47. Woo J (2007) Development of elderly care services in Hong Kong: challenges and creative solutions. Clin Med 7, 548-550.

48. Martinez ME, Marshall JR \& Sechrest L (1998) Invited commentary: factor analysis and the search for objectivity. Am J Epidemiol $148,17-19$. 